\title{
CENÁRIO INSTITUCIONAL NA PERSPECTIVA DE STAKEHOLDERS: ANALISANDO A APAE SETE LAGOAS
}

\author{
INSTITUTIONAL SCENARIO FROM THE STAKEHOLDERS \\ PERSPECTIVE: ANALYZING THE APAE SETE LAGOAS
}

\author{
José Edson Lara ${ }^{1}$ \\ Liza Kamei Rodrigues ${ }^{2}$ \\ Luiz Rodrigo Cunha Moura ${ }^{3}$ \\ Ronaldo Lamounier Locatelli ${ }^{4}$
}

\begin{abstract}
Resumo: O objetivo deste estudo é propor e analisar um modelo capaz de caracterizar e avaliar a percepção de stakeholders da APAE de Sete Lagoas, identificando seus níveis de envolvimento com a instituição. Realizou-se uma pesquisa qualitativa, com seis profissionais, e uma survey com amostra de 213 familiares da APAE-SL, de um total de 687 assistidos. Foram aplicados tratamentos de modelagem de equações estruturais, para se estudar os construtos e variáveis. Concluiu-se que as avaliações de "funcionários e atendimento" superam as avaliações sobre a "infraestrutura" da instituição. Sobre os aspectos estudados, as opiniões "após conhecer a APAE" é melhor do que a impressão que se tinha "antes de conhecê-la". Este relato contribui analisando um conjunto de construtos e variáveis que podem ser evoluídos para um modelo validado, capaz de demonstrar com profundidade as relações entre os stakeholders das APAEs. As contribuições gerenciais se justificam na oferta de um modelo aplicável por organizações.
\end{abstract}

Palavras-chave: APAE. Inclusão social. Stakeholder. Pessoa com deficiência.

Abstract: The objective of this study is to propose and analyze a model capable of characterizing and evaluating the perception of stakeholders of APAE in Sete Lagoas, identifying their levels of involvement with the institution. A qualitative research was carried out, with six professionals, and a survey with a sample of 213 family members of APAE-SL, from a total of 687 assisted. Structural equation modeling treatments were applied to study the constructs and variables. It was concluded that the evaluations of "employees and attendance" surpass those of the institution's "infrastructure". Regarding the aspects studied, the opinions "after knowing APAE" are better than the impression one had "before meeting it". This report contributes by analyzing a set of constructs and variables that can be developed into a validated model, capable of demonstrating in depth the relationships between the stakeholders of the APAEs. Management contributions are justified in offering a model applicable by organizations.

Keywords: APAE. Social inclusion. Stakeholder. Disabled person.

\footnotetext{
${ }^{1} \mathrm{PhD}$ em Economia de Empresas, pela Universitat Autònoma de Barcelona, Espanha. jedson.lara@ hotmail.com

${ }^{2}$ MS em Administração, pela Fundação Pedro Leopoldo, Minas Gerias. lizakameir@gmail.com

Dr. em Administração, pela Universidade Federal de Minas Gerais. luizrcmoura@gmail.com

PhD em Economia, pela London University, Reino Unido.ronaldo.locatelli@yahoo.com.br
}

\section{Cite como}

American Psychological Association (APA)

Lara, J. E., Rodriges, L. K., Moura, L. R. C., \& Locatelli, R. L. (2020, jul./dez.). Cenário institucional na perspectiva de stakeholders: analisando a APAE Sete Lagoas. Revista Inovação, Projetos e Tecnologias, São Paulo, 8(2), 255-269. https://doi.org/10.5585/iptec.v8i2.18411. 


\section{Introdução: contexto do tema e propósitos do relato}

\subsection{Sobre o contexto e propósitos do estudo}

A gestão de projetos sociais tem se manifestado como um tema fundamental no contexto da estratégia corporativa e institucional em todo o mundo mais desenvolvido, notadamente a partir do início do século XXI. As organizações vão se tornando cada vez mais complexas, inteligentes, sofisticadas e atuantes em conexões de negócios e atividades, em decorrência das novas demandas sociais, dos novos parâmetros de competitividade, das novas tecnologias e das novas estratégias de gestão. A intensa dinâmica dos negócios vai requerendo a consideração e adoção de novos propósitos e processos gerenciais, tanto em setores privados, como públicos e até das organizações não governamentais (ONGs). Assim, é natural que o próprio mercado disponibilize tecnologias gerenciais, especialmente a gestão de projetos corporativos, que objetivem a consecução de eficácia e eficiência, tão necessários às demandas sociais e da competitividade, especialmente na atuação com stakeholders. Assim, estes temas mostram presenças crescentes no contexto dos negócios (Carvalho \& Rabechini Jr., 2017).

$\mathrm{Na}$ literatura internacional e brasileira, a presença do tema gestão de stakeholders, incluindo nas ONGs, vem aumentando intensamente. Observa-se que periódicos científicos, técnicos e midiáticos de interesse geral vem abordando o tema, cada um ao seu propósito e formatos. A importância social da inclusão de indivíduos e comunidades, igualmente, vem sendo reconhecida por atores determinantes de políticas públicas, regulação e legislação, bem como pela sociedade (Mazzotta \& D’Antino, 2011) e (Silva, Oliveira \& Silva, 2018).

A Inclusão social consiste em oferecer oportunidades iguais às do restante da população para todas as pessoas que, por período provisório ou permanente, possuam necessidades especiais. Tais necessidades podem ser resultantes de condições atípicas, como as deficiências mentais, físicas, múltiplas, dificuldades de aprendizagem, insuficiências orgânicas, transtornos mentais ou outras (Sassaki, 1999). De acordo com a World Health Organization (WHO), (2011), mais de um bilhão de pessoas convivem com algum tipo de deficiência, ou seja, 15\% da população mundial. No Brasil, de acordo com o censo do Instituto Brasileiro de Geografia e Estatística (IBGE) de 2010, 45,6 milhões de pessoas, ou seja, 23,9\% da população, declararamse ter algum tipo de deficiência (visual, auditiva, motora, mental ou intelectual). Faz-se, então, necessário verificar se as pessoas com deficiência e suas famílias estão recebendo assistência, se estão sendo acolhidas, se existem serviços de habilitação e reabilitação para que haja uma melhora em sua qualidade. 
A Associação de Pais e Amigos dos Excepcionais (APAE), é uma associação civil e filantrópica, criada pelas famílias das pessoas com deficiência intelectual e múltipla com intuito de promover condições para que pessoas possam ser incluídas na sociedade e que tenham seus direitos garantidos, tendo sede e foro no município em que estiver situada" (FENAPAES, 2012, p. 6). Atualmente a APAE caracteriza-se como o maior movimento de filantropia em sua área de atuação no mundo, com 2.178 APAES e entidades filiadas, coordenadas por 24 Federações Estaduais, abrangendo todos os estados brasileiros para atender cerca de 250 mil pessoas com deficiência intelectual e múltipla diariamente (FENAPAES, 2012). Na área de saúde, a associação acompanha a pessoa com deficiência intelectual e múltipla em todo o seu ciclo de vida, em diversas especialidades médicas promovendo a prevenção e reabilitação. A assistência social garante direitos dos assistidos e suas famílias, capacita e habilita profissionais em diversos ofícios para que haja a absorção destas pessoas no mercado de trabalho e promove a melhoria da qualidade de vida.

Este relato se fundamenta na pergunta: qual é a caracterização e a percepção dos stakeholders no processo de gestão e manutenção da APAE de Sete Lagoas?

O objetivo geral é propor e avaliar um modelo capaz de caracterizar a percepção de grupos de stakeholders da APAE de Sete Lagoas (APAE-SL), analisando o nível de envolvimento destes grupos com a instituição. Os objetivos específicos são: 1) Identificar e caracterizar os stakeholders; 2) Caracterizar e analisar o perfil e os papéis dos seus stakeholders, a partir da percepção da diretoria e coordenadores; 3) Avaliar a opinião, do grupo de stakeholders assistidos e famílias, sobre diversos aspectos da instituição antes e depois de conhecer a APAE-SL; 4) Propor ações estratégicas de melhorias nas relações com os stakeholders.

A caracterização dos stakeholders de uma organização, permite conhecer com maior profundidade quais são as suas expectativas em relação ao trabalho que vêm sendo elaborado ao longo do tempo. Para a APAE-SL, este relato pretende apresentar as expectativas de alguns de seus Stakeholders em relação à instituição.

\section{Elementos da literatura}

\subsection{Sobre a pessoa com deficiência}

$\mathrm{Na}$ evolução do termo "pessoa com deficiência", a sociedade já nomeou a pessoa com deficiência de diversas outras formas. No Brasil, até a década de 1960, "aquele que tinha deficiência era tido como socialmente inútil, um peso morto para a sociedade, um fardo para a 
família, alguém sem valor profissional” (Sassaki, 2003, p. 1) e, por este motivo, era chamado de "inválido", "incapaz", "aleijado" e "defeituoso". Atualmente o termo adotado é "pessoa com deficiência".

A deficiência intelectual é caracterizada pela presença de insuficiências nas capacidades mentais, "como raciocínio, solução de problemas, planejamento, pensamento abstrato, juízo, aprendizagem acadêmica e aprendizagem pela experiência" (American Psychiatric Association - APA, 2014, p. 31). A Resolução n. 2/2.000, é considerada um dos documentos de maior importância na defesa da educação inclusiva no Brasil (Brandenburg \& Lückmeier, 2013), pois “institui as Diretrizes Nacionais para a educação de alunos que apresentem necessidades educacionais especiais, na Educação Básica, em todas as suas etapas e modalidades" (Resolução n. 2, 2001). Dentre outros aspectos, a Resolução trata da adaptação curricular para o atendimento ao aluno que apresentar necessidades educacionais especiais.

\subsection{Sobre a teoria dos stakeholders}

A teoria dos stakeholders (partes interessadas) emergiu em 1984, estabelecendo que stakeholder é qualquer pessoa ou grupo que possa influenciar a obtenção dos objetivos organizacionais, ou que possa ser afetado pelo processo de busca destes objetivos. A teoria mostra a relação da organização com o ambiente em que ela está inserida, bem como o seu comportamento neste ambiente, conforme Figura 1.

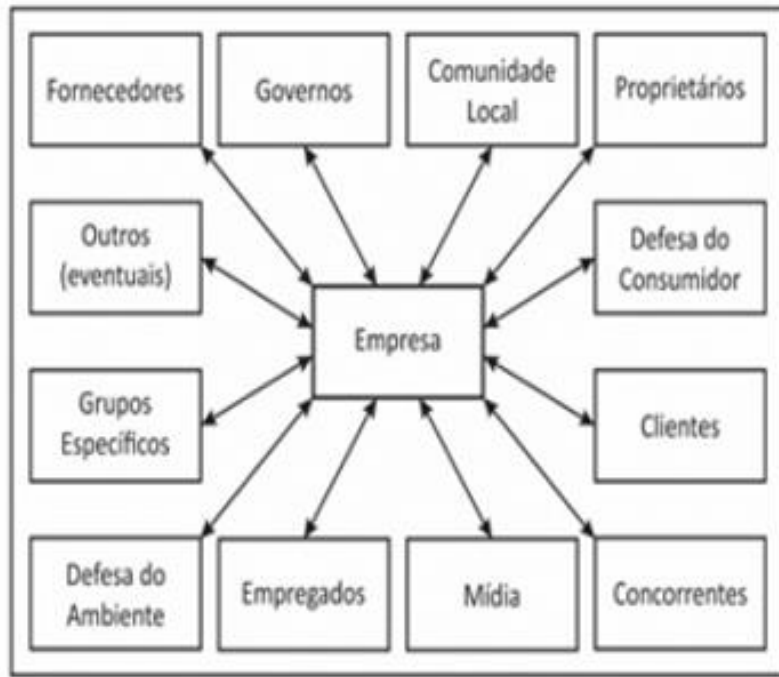

Figura 1: Modelo Original e Modelo Analitico da pesquiga

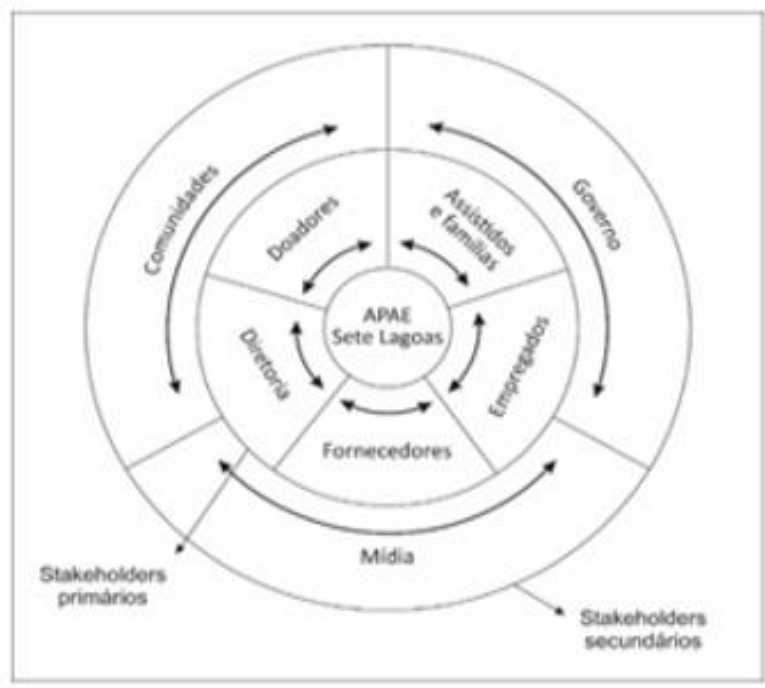

Fonte: Os autores. 
A Figura 1 mostra que os stakeholders se ligam à empresa através de setas duplas. Isto demonstra que existe uma interação entre a empresa e todos os stakeholders, em que os negócios da empresa influenciam os stakeholders e eles, por sua vez, exercem influência sobre os seus negócios. Para a APAE-SL, considera-se interessante conhecer bem seus stakeholders, permitindo-lhe se posicionar perante cada um deles, adequando-se e buscando parâmetros de efetividade estratégica e estrutural. Assim o modelo estrutural do sistema APAE-SL, está definido conforme Figura 2. Este modelo configura, também o Modelo Analítico da pesquisa. A premissa é que o grau de envolvimento de cada um em uma organização normalmente varia em intensidade, momento, forma de participação, contribuições e outras idiossincrasias.

\section{Metodologia e procedimentos metodológicos}

Os procedimentos metodológicos do estudo visaram ao atendimento da natureza de um relato técnico, tal como recomendam Biancolino, Kniess, Maccari e Rabechini Jr., (2010).

\subsection{Sobre o projeto de pesquisa}

Este estudo caracteriza-se como um relato descritivo, documental, quantitativo e qualitativo. sobre a APAE- SL. A instituição está em funcionamento desde o ano de 1970, atende à 687 pessoas com deficiência intelectual e múltipla e suas famílias. As unidades de observação foram os grupos de stakeholders identificados na Figura 2: governo, mídia, doadores, comunidades, assistidos, diretoria, empregados e fornecedores, sob o ponto de vista da diretoria, coordenadores e familiares. A pesquisa empírica foi realizada nos meses de agosto e setembro de 2019. Foram aplicadas duas técnicas para coleta de dados: entrevista semiestruturada com alguns de seus coordenadores e uma survey, aplicando-se um questionário estruturado. Os questionários foram aplicados em uma amostra de 213 familiares da APAE-SL, de um total de 687 assistidos.

\subsection{Sobre os fundamentos do projeto}

Responsáveis pela pesquisa da literatura e de campo: os próprios autores deste relato;

\section{Responsabilidade pela interlocução com a instituição: Liza Kamei;}

Tema central do projeto: análise do cenário institucional da APAE-SL, na perspectiva de stakeholders: primários (internos) e secundários (amostra de 213 familiares); 
Fonte de financiamento e valores envolvidos: a pesquisa não recebeu financiamento externo;

Tipo de intervenção e mecanismos adotados: consistiu de uma pesquisa empírica, em conformidade com os rigores científicos e técnicos

\subsection{Sobre a organização e a situação-problema}

A APAE-SL foi criada em 1968 e desde 1970 está afiliada à Federação das APAES do Estado de Minas Gerais. É uma Organização da Sociedade Civil (OSC), sem fins lucrativos, possuindo o certificado de Utilidade Pública e Certificado de Entidade Beneficente De Assistência Social (CEBAS), concedido pelo Governo Federal. Fornece atendimento à pessoa com deficiência intelectual e múltipla e suas famílias, atendendo pessoas residentes em Sete Lagoas e 23 municípios. Para a manutenção dos serviços, a APAE-SL mantém convênios e parcerias com órgãos do primeiro e segundo setores da economia. Sendo a APAE prestadora de serviços do SUS, a clínica da instituição participa do Programa de Intervenção Precoce Avançado - PIPA sendo um Centro Especializado em Reabilitação (CER). Dentre os serviços prestados, podem ser destacados: Abordagem familiar - anamnese social e de saúde; Projeto primeiros passos - neonatos. Avaliação multidimensional - projeto biopsicosocial; Atendimentos clínicos individuais; Projeto bem viver - desenvolvimento motor e cognitivo grave - paralisias cerebrais ou portadores de síndromes complexas; Projeto de orientação periódica aos assistidos; Projeto passarinhos - intervenção precoce para crianças de zero a três anos; Projeto musicalização; Projeto biodança; Projeto cinoterapia; Projeto consultoria escolar; Projeto tagarelas - para pessoas com deficiências de linguagem; Projeto Livox - melhoria de comunicação. Projeto equoterapia; Projeto afetivo sexual; Escola Oficina Rodolfo Pontello de Freitas; Assistência social aos assistidos e familiares; Serviço de proteção social especial; Projeto Trocando ideias; Escola de autodefensores; Programa de promoção de capacitação e promoção da integração ao mercado de trabalho; Escola de Família; Em essência, a situaçãoproblema da instituição consiste em que ela não conhece, com precisão, o nível de envolvimento de seus stakeholders, notadamente os mais externos. Por isto, a gestão é muito intuitiva, nas relações e negociações com todos os stakeholders. 


\section{Apresentação e análise dos resultados}

\subsection{Conteúdo da pesquisa qualitativa}

Esta pesquisa foi realizada com seis membros da diretoria e coordenadores da APAESL, representando 8 grupos de stakeholders, considerados primários e secundários. Todos afirmam que os serviços prestados pela APAE-SL são de grande importância para a sociedade, visto que a instituição é única no que se propõe, na região. Entre as manifestações, podem ser destacadas as seguintes: "Nós cobrimos uma lacuna deixada pelos governos federal, estadual e municipal, que é o tratamento de saúde das pessoas com deficiência intelectual, deficiência física e autismo. (C01); “A importância é grande para a comunidade, pois hoje o atendimento da APAE é único. Só existe a APAE e o atendimento que ela presta à comunidade é diferenciado e só vem a somar para a comunidade” (V02); e, "A importância vem com a implementação de políticas públicas. E agora com o serviço do CER vamos começar a fornecer as cadeiras de rodas, de banho e outras e isto irá impactar muito a comunidade”(C04).

Todos os entrevistados apontaram a falta de informação como o maior causador da existência dos mitos da comunidade em relação aos serviços da APAE-SL. Como exemplo, tem-se a declaração: "Hoje tratamos, além das deficiências intelectuais, o autismo e deficiência física, temos também os neonatos de risco que são pacientes que, a princípio, não apresentam nenhuma deficiência. Por esta razão as famílias têm muita dificuldade em trazê-los para a APAE, pois não entendem a APAE como uma clínica de saúde, como um Centro Especializado em Reabilitação. Entretanto tem-se manifestações tais como esta: "A APAE faz tudo por isso, ela vai seguindo em etapas e, na última etapa, o assistido já está apto a conviver em sociedade" (V02). Sobre o apoio governamental, extraiu-se estas afirmações: "Eles demonstram interesse justamente porque existe essa lacuna que eles não conseguem cobrir, então acredito que eles tenham interesse na existência da APAE. (C01); “O poder público não consegue realizar o serviço de excelência com a estrutura que a APAE tem. É uma parceria existente que acaba sendo boa para os dois lados” (C04).

Sobre a importância da mídia para a APAE-SL, destaca-se a observação: "O surgimento do setor de comunicação na APAE de Sete Lagoas foi o que mais contribuiu para que a APAE tivesse mais visibilidade e o apoio da comunidade (C01). O sucesso na interação com a mídia permitiu a melhoria significativa na captação de recursos comunitários para financiamento de atividades operacionais. A percepção dos stakeholders primários sobre os demais agentes colaboradores, se manifesta em declarações tais como estas: “A maior importância na clínica de saúde é o atendimento multidisciplinar. O paciente tem todas as terapias que ele precisa no 
mesmo lugar, com pessoas especializadas em suas deficiências” (CO1); “Cada usuário possui o seu "Plano de Acompanhamento Familiar" e, de acordo com ele, são traçados metas $e$ objetivos para que cada usuário e familiar possa evoluir dentro de suas possibilidades" (C03); Sobre os funcionários, sobressai esta afirmação: “Lugar que cuida de pessoas.... Essas pessoas também têm que ser cuidadas. (CO4). Sobre os fornecedores exibe-se esta percepção: "todos os fornecedores que negociamos, quando falamos que é para a APAE, têm um desconto, um atendimento diferenciado por ser para a APAE” (V02). No que tange às doações, relevam-se: "A gente recebe muitas pessoas que aparecem expontaneamente CO1) e "Tem pessoas que contribuem só de saber que a doação é para a APAE. Elas depositam na conta ou realizam jogos nas empresas com a arrecadação destinada à APAE” (V02). Com estas manifestações literais, conclui-se que a atuação da APAE-SL tem sido bem compreendida e bem sucedida em seus propósitos e processos institucionais, ainda que haja, reconhecidamente, aspectos a serem melhorados, declarados pelos stakeholders primários.

\subsection{Conteúdos da pesquisa quantitativa}

Nesta pesquisa foram obtidos 211 questionários preenchidos, com 39 questões paramétricas. Identificou-se e eliminou-se o total dos outliers multivariados. A identificação dos outliers apurou-se pelo cálculo do valor da Distância $\mathrm{D}^{2}$ de Mahalanobis e do cálculo do valor do Teste do $X^{2}$ (sig. $=0,001$ e df $=39$ e pela comparação dos dois valores. Foram retirados 29 elementos da amostra, que a conter um total de 182 casos. A verificação da normalidade da amostra foi executada com o Teste de Kolmogorov-Smirnov. Os resultados indicaram violação da normalidade, com um $p$-valor $=0,000$. Foi feita a descrição das características da amostra, sendo formada por respondentes que são mães ou pais - mais de $84 \%$ - de crianças e adolescentes - mais de $80 \%$ - que são assistidos pela APAE-SL. A seguir verificou-se as dimensões presentes nas avaliações dos respondentes. Foram realizadas análises fatoriais exploratórias (AFE), uma para as respostas que consideram as percepções "antes de conhecer a APAE" e outra para as respostas que consideram as percepções "depois de conhecer a APAE". O método de extração nessa primeira etapa para a AFE foi o de fatoração de eixos principais, pois, o objetivo foi o de identificar os construtos presentes. Para alocar os indicadores para os seus respectivos construtos, foi realizada a rotação ortogonal pelo método varimax.

Alguns indicadores não foram agrupados em nenhum dos dois fatores gerados pela AFE. Dos 19 indicadores presentes na AFE, seis deles - que se iniciam com a expressão "antes de conhecer a APAE” se encaixam nessa situação: “eu considerava que ela cumpriria com as 
promessas que faz", "eu considerava que ela compreende o usuário quando ele tem algum problema", "eu considerava que a APAE cumpriria com os prazos prometidos ao prestar seus serviços", "eu considerava que a APAE mantinha os registros dos assistidos", "eu considerava que a APAE atenderia os usuários e famílias com horário marcado" e "eu considerava que a instituição saberia dos interesses de usuários e famílias”.

Os resultados indicam ainda que o construto de qualidade de APAE - "Antes de conhecer a APAE" é formado por dois construtos: "Funcionários e Atendimento" e "Infraestrutura" - ver Tabela 2. Ressalta-se que todos os três pressupostos para a realização da AFE foram atendidos e que os valores da comunalidade e do componente foram superiores a 0,500 para todos os indicadores dos dois construtos. O método de extração para essa e a próxima AFE foi o de componentes principais.

De forma análoga à que ocorreu com os indicadores relativos à percepção dos respondentes antes de conhecer a APAE, foi feita uma AFE exploratória com os resultados das percepções após conhecerem a APAE. Foram obtidos três fatores que constituem os 19 indicadores. Todavia, somente um indicador do fator F3 apresentou valores adequados. Para possibilitar o processo de comparação entre as duas situações - antes e depois de conhecer - a APAE, inclusive por meio da modelagem de equações estruturais - optou-se por fazer um teste com os 19 indicadores que retratam a percepção após conhecer a APAE. Da mesma forma que ocorreu com os dois construtos "antes de conhecer a APAE", o resultado da AFE com os dois construtos "depois de conhecer a APAE", "Funcionários e Atendimento" e "Infraestrutura" atenderam os três pressupostos para a realização das AFE, bem como os valores do componente e da comunalidade de todos os indicadores possuem valores acima de 0,500.

Para averiguar a confiabilidade das escalas foi utilizado o valor do Alpha de Cronbach (AC), cujos resultados foram bastante positivos (Tabela 1), pois todos os construtos apresentaram valores para o AC superiores a 0,80 . Foi feita a avaliação da validade convergente dos quatro construtos gerados antes e depois de conhecer a APAE. Para examinar a validade convergente são utilizados dois indicadores: a Variância Média Extraída (AVE) e a Confiabilidade Composta. Analisando-se os resultados da Tabela 1, verifica-se que eles são muito bons, pois, todos os valores para a AVE e para a CC estão acima dos valores de referência. Há de se considerar também que os dois construtos gerados representam a percepção dos respondentes sobre a atuação dos funcionários e do atendimento da APAE, bem como a percepção sobre a infraestrutura da instituição. 
Tabela 1 - Características psicométricas dos construtos e dos indicadores do modelo de qualidade percebida antes e depois de conhecer a APAE

\begin{tabular}{|c|c|c|}
\hline Construto / Descrição do Indicador & $\begin{array}{l}\text { Média }^{7} \\
\text { Antes }\end{array}$ & $\begin{array}{l}\text { Média }^{7} \\
\text { Depois }\end{array}$ \\
\hline $\begin{array}{l}\text { Antes - Funcionários e Atendimento } \mathrm{VE}^{2}=69,65 \% \mathrm{KMO}^{3}= \\
0,937 \mathrm{AC}^{4}=0,951 \mathrm{AVE}^{5}=0,730 \mathrm{CC}^{6}=0,964\end{array}$ & 4,88 & \\
\hline $\begin{array}{l}\text { Depois - Funcionários e Atendimento } \mathrm{VE}^{2}=59,76 \% \mathrm{KMO}^{3}= \\
0,913 \mathrm{AC}^{4}=0,920 \mathrm{AVE}^{5}=0,701 \mathrm{CC}^{6}=0,874\end{array}$ & & 6,75 \\
\hline A instituição seria confiável. & 5,47 & 6,87 \\
\hline $\mathrm{O}$ atendimento da APAE seria rápido. & 4,07 & 6,62 \\
\hline $\begin{array}{l}\text { Os funcionários da APAE estariam sempre dispostos a ajudar aos } \\
\text { usuários e famílias }\end{array}$ & 4,92 & 6,81 \\
\hline Os usuários e famílias poderiam confiar nos funcionários da APAE. & 5,13 & 6,80 \\
\hline Os usuários se sentiriam seguros dentro da APAE. & 5,02 & 6,84 \\
\hline Os funcionários seriam educados. & 5,30 & 6,76 \\
\hline Os funcionários teriam apoio da APAE para fazer seu trabalho. & 4,92 & 6,58 \\
\hline Os serviços seriam feitos com atenção personalizada (individual). & 4,59 & 6,76 \\
\hline Os funcionários dariam atenção especial aos usuários. & 4,83 & 6,78 \\
\hline $\begin{array}{l}\text { Os funcionários saberiam quais são as necessidades dos usuários e } \\
\text { famílias. }\end{array}$ & 4,54 & 6,71 \\
\hline $\begin{array}{l}\text { Antes - Infraestrutura } \mathrm{VE}^{2}=79,35 \% \mathrm{KMO}^{3}=0,700 \mathrm{AC}=0,870 \\
\mathrm{AVE}^{5}=0,624 \mathrm{CC}^{6}=0,943\end{array}$ & 4,22 & \\
\hline $\begin{array}{l}\text { Depois - Infraestrutura } \mathrm{VE}^{2}=73,92 \% \mathrm{KMO}^{3}=0,683 \quad \mathrm{AC}^{4}= \\
0,804 \mathrm{AVE}^{5}=, 624 \mathrm{CC}^{6}=0,830\end{array}$ & & 6,62 \\
\hline Ela teria equipamentos modernos. & 3,90 & 6,45 \\
\hline Ela teria facilidade no acesso físico. & 4,34 & 6,71 \\
\hline Ela teria instalações físicas adequadas aos serviços prestados. & 4,43 & 6,70 \\
\hline
\end{tabular}

Notas: 1) todas os indicadores dos construtos antes são precedidos da expressão "antes de conhecer a APAE eu considerava que...". Todos os indicadores dos construtos depois são precedidos da expressão "após conhecer a APAE eu constatei que....” 2) VE é a variância explicada pelo fator. 3) KMO é o valor do Teste KMO. 4) AC é o Valor do Alpha de Cronbach. 5) AVE é a variância média explicada 6) CC é a confiabilidade composta. 7) Esse valor representa a média entre os valores de 1 a 7.

Fonte: Dados da pesquisa.

Pela Tabela 1 verifica-se que as médias para os valores depois de conhecer a APAE são muito maiores do que as médias antes de conhecer a APAE. Assim, foi realizado um Teste T de comparação entre duas médias para todos os indicadores desses dois construtos. Os resultados são conclusivos em termos das diferenças serem estatisticamente significativas. Outra questão abordada na pesquisa é a probabilidade do respondente em recomendar a APE para outras famílias. A escala varia entre 0 e 10 e a média foi de 9,87 , o que indica que a grande 
maioria dos respondentes indica a APAE. Esse resultado é coerente com a boa avaliação da qualidade percebida pelos pais dos assistidos.

Foi verificada a validade discriminante em relação aos construtos Antes e Depois. A existência da validade discriminante indica que dois construtos não são redundantes entre si e que apesar de compartilharem algum nível de variância, eles representam construtos realmente distintos e que a variância que formam esses construtos é maior do que a correlação deles com outros construtos. Assim, dois construtos distintos apresentam um valor baixo para a correlação entre si (Hair et al., 2009; Malhotra, 2011). A validade discriminante é examinada por meio dos pares de construtos. Assim, são comparados os valores da raiz quadrada da AVE de cada construto com o valor da correlação entre esses construtos. Esse último valor deve ser maior do que o valor da correlação entre os dois construtos que formam o par (Hair et al., 2009). O valor das correlações entre os construtos Antes e a comparação com o valor da raiz da A.V.E. são apresentados pela Tabela 2 a seguir:

Tabela 2 - Valor das correlações e da raiz quadrada da A.V.E. para os construtos Antes

\begin{tabular}{|c|c|c|c|}
\hline & $\begin{array}{l}\text { Antes F1 - } \\
\text { Funcionários e } \\
\text { Atendimento }\end{array}$ & $\begin{array}{l}\text { Antes F2 - } \\
\text { Infraestrutura }\end{array}$ & $\begin{array}{l}\text { Intenção de } \\
\text { Recomendar }\end{array}$ \\
\hline $\begin{array}{l}\text { Antes F1 - Funcionários e } \\
\text { Atendimento }\end{array}$ & $\mathbf{0 , 8 5}$ & & \\
\hline Antes F2 - Infraestrutura & 0,76 & $\mathbf{0 , 8 4}$ & \\
\hline Intenção de Recomendar & 0,09 & $-0,17$ & $\mathbf{0 , 8 2}$ \\
\hline
\end{tabular}

Fonte: Dados da pesquisa.

O valor da AVE utilizado para o construto recomendação foi de 0,67 que é a média da AVE dos construtos Antes F1 - Funcionários e Atendimento, Antes F2 - Infraestrutura, Depois F1 - Funcionários e Atendimento e Depois F2 - Infraestrutura. A diagonal principal da Tabela 3 - em negrito - representa os valores da raiz quadrada da AVE. De acordo com os resultados obtidos, verifica-se a existência da validade discriminante para os três construtos. Em relação à verificação da validade discriminante para os construtos Depois de conhecer a APAE e a recomendação, os resultados estão presentes na Tabela 3 a seguir. 
Tabela 3 - Valor das correlações e da raiz quadrada da ave para os construtos Depois

\begin{tabular}{|c|c|c|c|}
\hline & $\begin{array}{l}\text { Depois F1 - Funcionários } \\
\text { e Atendimento }\end{array}$ & $\begin{array}{l}\text { Depois F2 - } \\
\text { Infraestrutura }\end{array}$ & $\begin{array}{l}\text { Intenção de } \\
\text { Recomendar }\end{array}$ \\
\hline Depois F1 - Funcionários e Atendimento & 0,79 & & \\
\hline Depois F2 - Infraestrutura & 0,80 & $\mathbf{0 , 7 9}$ & \\
\hline Intenção de Recomendar & 0,86 & 0,84 & $\mathbf{0 , 8 2}$ \\
\hline
\end{tabular}

Fonte: Dados da pesquisa.

A diagonal principal da Tabela 3 representa os valores da raiz quadrada da AVE do respectivo construto. Verifica-se que não existe validade discriminante entre os três construtos. Assim, os resultados a serem obtidos na validade nomológica e verificação da associação entre os construtos Depois F1 Funcionários e Atendimento e Depois F2 Infraestrutura com a recomendação de indicar a APAE devem levar em consideração essa limitação. Foi realizada uma modelagem de equações estruturais multigrupo, cujo resultado indica que as diferenças entre os valores dos coeficientes dos grupos "antes" e "depois" são estatisticamente significativos em nível de 0,05, pois, o valor do $p$-sig. foi de 0,02. Mais especificamente, a relação entre Funcionários e Atendimento X Recomendação passou de um valor $\beta=0,24$ para um valor $\beta=0,68$ e a relação entre Infraestrutura $X$ Recomendação passou de um valor $\beta=$ 0,24 para um valor $\beta=-0,09$. Por conseguinte, as relações entre os construtos e a sua influência no comportamento de recomendar a APAE é maior para o grupo de respondentes que conhecem a APAE do que para aqueles que ainda não conhecem. Assim, este relato permite concluir que o conhecimento sobre a APAE aumenta muito a possibilidade dos responsáveis pelos assistidos em fazer uma propaganda boca a boca positiva para a APAE.

\section{Considerações finais}

Conclui-se que a APAE-SL é uma instituição que presta diversos serviços relevantes para a pessoa com deficiência e suas famílias. Pelos trabalhos realizados pela instituição, é possível a inclusão social, trazendo benefícios para o assistido, família e sociedade, proporcionando melhores níveis de educação a pessoas especiais. Os stakeholders da APAESL, sendo diversificados e complexos, beneficiam a instituição e usuários através de doações, parcerias, divulgação e participação nos eventos, repasses financeiros, trabalho com comprometimento e voluntariado, devendo, portanto, ser estudados com profundidade científica e técnica. Assistidos e famílias, considerados um importante grupo primário de stakeholders, assumem diversas expectativas em relação à APAE-SL. As famílias, de acordo com alguns entrevistados, realizam reinvindicações, diante de necessidades de mudanças na 
instituição. Os serviços da APAE-SL, “cobrem uma lacuna” deixada pelo governo, que não consegue oferecer tudo o que a instituição oferece aos usuários.

Verificou-se que os valores atribuídos aos diversos aspectos da instituição para "Antes de conhecer a APAE" foram menores que as notas de "Depois de conhecer a APAE". Os resultados foram positivos e apresentam altas médias, acima de $90 \%$ para todas as opções. Em algumas questões, a totalidade das respostas foi de alguma forma positiva em relação aos funcionários e atendimento prestado pela APAE. Pode-se correlacionar este resultado com a fala de um dos entrevistados (C04) que afirmou que a APAE-SL já foi chamada de "depósito de gente". Hoje, sabe-se da seriedade da instituição no sentido da melhoria da qualidade de vida, promovendo a inclusão social, reabilitação, saúde, atividades da vida prática e diária, para que a pessoa possa conviver em sociedade e tenha maior independência.

Por conseguinte, as relações entre os construtos e a sua influência no comportamento de recomendar a APAE é maior para o grupo de respondentes que conhecem a APAE do que para aqueles que ainda não conhecem. Assim, pode-se concluir que o conhecimento e o engajamento dos stakeholders sobre a APAE aumenta muito a possibilidade dos responsáveis pelos assistidos em fazer uma propaganda boca a boca positiva, além de recomendar a organização como instituição inclusiva.

As contribuições deste trabalho são duais. Primeiramente destaca-se a elaboração e o teste de um instrumento de coleta de dados para a mensuração da qualidade percebida pelos responsáveis pelos assistidos, a partir de uma pesquisa qualitativa e depois, o seu teste empírico por meio de uma pesquisa de abordagem quantitativa. Além disso, descobriram-se os fatores ou dimensões que representam em grande parte essa percepção de qualidade.

Em termos das contribuições gerenciais, destaca-se que o desenvolvimento de um instrumento de pesquisa capaz de captar a percepção de qualidade dos responsáveis pelos assistidos apresenta grande relevância, pois, pode servir como instrumento de controle e de avaliação pelos gestores das APAEs, acerca dos seus projetos e das atividades operacionais em relação ao trabalho realizado com os assistidos. Neste quesito a contribuição mais relevante deste relato técnico consiste na proposição e teste do modelo com os construtos e variáveis.

No caso das limitações deste trabalho, a principal delas está relacionada com a amostragem, que não é probabilística. Ressalta-se ainda que a APAE-SL atende a um número muito maior de assistidos, e, consequentemente de responsáveis, do que o tamanho final da amostra, o que suscita a possibilidade da opinião dos entrevistados serem diferentes da opinião dos que não participaram da pesquisa. 
Recomenda-se ainda a continuidade de novos estudos, considerando-se a realização de uma pesquisa com os próprios assistidos. Outra possibilidade é a de identificar as prioridades para os responsáveis pelos assistidos, bem como de realizar essas pesquisas em várias unidades da APAE, de preferência em diferentes regiões do Brasil.

\section{Referências}

Almeida, P. (2018). Falando sobre deficiência - guia para a imprensa. Recuperado de https://docs.wixstatic.com/ugd/d8efe7_6dda6ff76d684819abbc7c1f10d1b70e.pdf.

American Psychiatric Association (APA). (2014). Manual diagnóstico e estatístico de transtornos mentais: DSM-5. (5a ed.). Recuperado de https://aempreendedora.com.br/wpcontent/uploads/2017/04/Manual-Diagn\%C3\%B3stico-e-Estat\%C3\%ADstico-deTranstornos-Mentais-DSM-5.pdf.

Aoki, M., Silva, R. M., Souto, A. C. F. \& Oliver, F. C. (2018). Pessoas com deficiência e a construção de estratégias comunitárias para promover a participação no mundo do trabalho. Revista brasileira de educação especial. 24(4), 517-534, doi 10.1590/s141365382418000500004 .

Biancolino, A. C.; Kniess, C. T.; Maccari, E. A. \& Rabechini Jr., R. (2012). Protocolo para elaboração de relatos de produção técnica. Revista de Gestão e Projetos - GeP, São Paulo, v. 3, n. 2, p 294-307, mai./ago. DOI:10.5585/gep.v3i2.121.

Brandenburg, L. E. \& Lückmeier, C. (2013). A história da inclusão x exclusão social na perspectiva da educação inclusiva. Anais do Congresso Estadual de Teologia. São Leopoldo, RS, Brasil, 1, 175-186. Recuperado de http://anais.est.edu.br/index.php/teologiars/article/download/191/149

Carvalho, M. M. \& Rabechini Jr., R. (2017). Fundamentos em Gestão de Projetos. São Paulo. Atlas.

Constituição da República Federativa do Brasil. (1988, 05 de outubro). Disponível em http://www.senado.gov.br/sf/legislacao/const/

Coutinho, K. S., Rodrigues, G. F. \& Passerino, L. M. (2017). O trabalho de colaboradores com deficiência nas empresas: com a voz os gestores de recursos humanos. Revista brasileira de educação especial. 23(2), 261-278, doi 10.1590/s1413-65382317000200008.

Federação Nacional das APAES (FENAPAES). (2016). O que fazemos. Recuperado de http://apae.com.br/.

Federação Nacional das APAES (FENAPAES). (2012). Manual de fundação das Apaes. Recuperado de http://apaebrasil.org.br/uploads/Manual\%20Apae.pdf.

Freeman, R. E. (1984). Strategic management: a stakeholder approach. Boston: Pitman Hair, J. F., Black, W. C., Babin, B. J., Anderson, R. E., \& Tatham, R. L (2009). Análise multivariada de dados. Porto Alegre: Bookman Editora. 
Instituto Brasileiro de Geografia e Estatística (IBGE). (2010a). Censo demográfico 2010: características gerais da população, religião e pessoas com deficiência. Rio de Janeiro: Recuperado: https://biblioteca.ibge.gov.br/visualizacao/periodicos/cd_2010_religiao_deficiencia.pdf.

Malhotra, N. K. (2011). Pesquisa de Marketing: Uma Orientação Aplicada. Porto Alegre: Bookman Editora.

Mazzotta, M. J. S. \& D’Antino, M. E. F. (2011). Inclusão social de pessoas com deficiências e necessidades especiais: cultura, educação e lazer. Saúde e Sociedade, 20(2), 377-389. Recuperado de https://www.scielosp.org/pdf/sausoc/2011.v20n2/377-389/pt.

Organização Mundial da Saúde (OMS). (2014). CID-10: classificação estatística internacional de doenças e problemas relacionados à saúde. (10a ed.) São Paulo: EDUSP.

Pacheco, K. M. D. B. \& Alves, V. L. R. (2007). A história da deficiência, da marginalização à inclusão social: uma mudança de paradigma. Acta Fisiátr, 14(4), 242-248. Recuperado de http://www.revistas.usp.br/actafisiatrica/article/view/102875/101168.

Resolução CNE/CEB, n. 2, de 11 de setembro de 2001. Disponível em http://portal.mec.gov.br/cne/arquivos/pdf/CEB0201.pdf.

Sassaki, R. K (2003). Como chamar as pessoas que têm deficiência? Revista da Sociedade Brasileira de Ostomizados. 1(1), 8-11.

Silva, M. V. P., Oliveira, G. V. O. \& Silva, L. B. (2018). Inclusão social: por uma educação humana. Anais do Congresso Internacional de Educação Inclusiva. Campina Grande, PB, Brasil, 3, 1-2. Recuperado de http://www.editorarealize.com.br/revistas/cintedi/trabalhos/TRABALHO_EV110_MD4_SA 23_ID1696_12082018202302.pdf.

Vivarta, V. (2003). Mídia e deficiência. Recuperado de http://www.andi.org.br/sites/default/files/Midia_e_deficiencia.pdf.

World Health Organization [WHO]. (2011). World report on disability 2011. Recuperado de http://www.who.int/disabilities/world_report/2011/report.pdf. 